\title{
Taylor's Approach to Rescue: A Case of Undiagnosed Alkaptonuria Undergoing Bilateral Total Knee Replacement
}

\author{
Bhimala Naga Ramya ${ }^{1}$, Sujil Sudhersan ${ }^{2}$, Sivakumar Segaran ${ }^{3 *}$ \\ ${ }^{1,2}$ Junior Resident, ${ }^{3}$ Associate Professor, Department of Anaesthesiology and Critical care, \\ Pondicherry Institute of Medical Sciences, India
}

\begin{abstract}
Alkaptonuria is a rare inherited autosomal recessive metabolic disorder due to the deficiency of homogentisic acid oxidase resulting in accumulation of homogentisic acid in collagen and cartilaginous tissue resulting in stiffening of joints, spine and involving other systems which pose challenges to anaesthesiologist in providing anaesthesia. Here we present a patient with undiagnosed alkaptonuria who was posted for bilateral total knee replacement. Since these patients usually have reduced intervertebral spaces, neuraxial anaesthesia was difficult with classic approach. Taylor's approach was used for neuraxial anaesthesia and, post-operative analgesia was achieved with continuous femoral nerve block with catheter placement.
\end{abstract}

Key words: alkaptonuria, Taylor's approach, total knee replacement, regional anaesthesia, femoral nerve block

\section{Introduction}

Alkaptonuria is a rare autosomal recessive inherited metabolic disorder where the enzyme homogentisic acid oxidase is deficient which is needed for tyrosine metabolism. It is characterized by the triad of homogentisic aciduria, ochronosis, and arthritis. ${ }^{1,2}$ Its reported incidence is about 1 in $2,50,000$ to 1 in $10,00,000 .{ }^{3}$ The clinical manifestations are due to the accumulation of an ochre coloured homogentisic acid in the cartilages and connective tissues. ${ }^{2}$

We present a case of alkaptonuria posted for total knee replacement for whom classical neuraxial technique failed, so Taylor's approach was used as a rescue technique and post-operative analgesia was achieved by continuous femoral nerve block.

*Correspondence: Sivakumar Segaran

E mail: siva85dr@gmail.com

https://orcid.org/0000-0002-5409-5274

Received: 19/12/2020

Accepted: 22/08/2021

DOI: https://doi.org/10.4038/slja.v29i2.8743

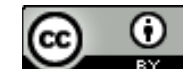

\section{Case report}

A 58-year-old male patient with a BMI of $21.3 \mathrm{~kg} / \mathrm{m}^{2}$, and bilateral knee joint osteoarthritis came for bilateral total knee replacement. He presented with complaints of bilateral knee joint pain for the past 6 months, hindering his daily activities. He also had low back pain and joint stiffness. He had no other comorbidities and had a good effort tolerance. On examination, vitals were stable. Airway assessment revealed Mallampati class 4 and restricted neck extension with adequate mouth opening. Examination of lumbar spine showed narrowed intervertebral spaces on palpation. Blood investigations were within normal limits. Chest X-Ray, ECG and echocardiogram were unremarkable. Initially the patient was posted for left knee arthroplasty. We planned to proceed under combined spinal epidural anesthesia after obtaining informed consent. After positioning the patient seated, 18G Touhy epidural needle was attempted at the L3L4 space under strict aseptic precautions. Multiple attempts in both midline and paramedian approaches at different levels were unsuccessful. Hence the procedure was abandoned. Then we attempted to give a subarachnoid block at L3-L4 space both paramedian and midline approaches using a $25 \mathrm{G}$ Quincke needle but failed. So as a final attempt 
Taylor's approach was considered and was successful. After free flow of CSF, $2.8 \mathrm{ml}$ of $0.5 \%$ heavy bupivacaine and $0.2 \mathrm{ml}$ of $30 \mathrm{mcg}$ clonidine were given. Block was adequate and achieved up to T6 level. Intra-operatively, the orthopedic surgeon alerted us regarding the dark pigmentation of the knee joint cartilage. Ochronosis was then implicated to be the cause for arthritis and the difficulty in providing neuraxial anaesthesia. Throughout the procedure patient was hemodynamically stable. Surgery lasted for 2 hours with a blood loss of $600 \mathrm{ml}$. Postoperatively pain was managed with a continuous femoral nerve block infusion with $5 \mathrm{ml} / \mathrm{hr}$ of $0.25 \%$ levobupivacaine. Femoral catheter was left in place for 48 hours post operatively and patient was pain free with a visual analogue score of less than 3 throughout the 48 hour period. No rescue analgesic was needed, and patient was able to mobilize.

Post operatively the patient was further evaluated for suspected alkaptonuria. On systemic examination, X-ray lumbar spine showed degenerative changes with disc space narrowing and calcification indicating Baffle's sign of spine.

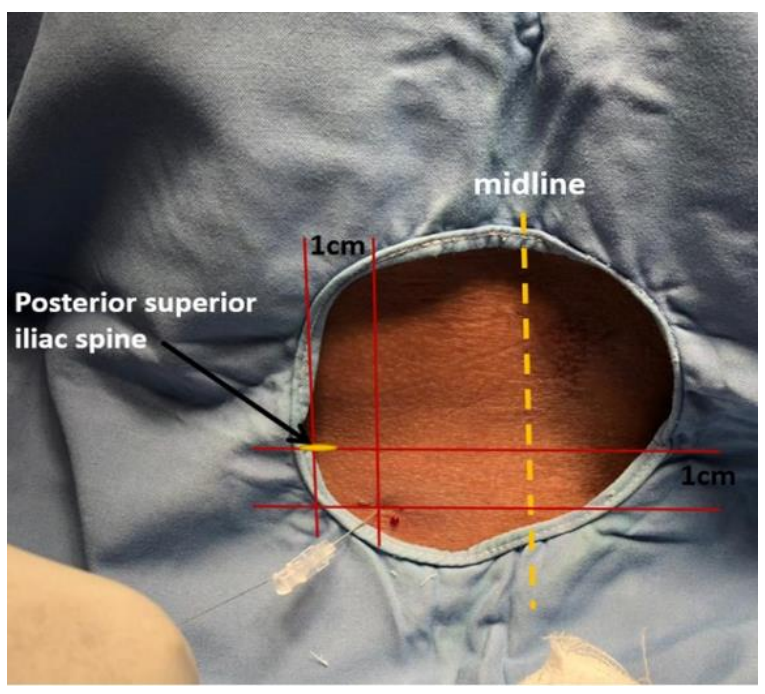

Figure 1. Taylor's approach

Urine was tested which turned black after few hours on exposure to air. Histopathological evaluation showed characteristic extensive brownish black discolouration involving the cartilage and fibro collagen confirming the diagnosis of endogenous ochronosis (Alkaptonuria).

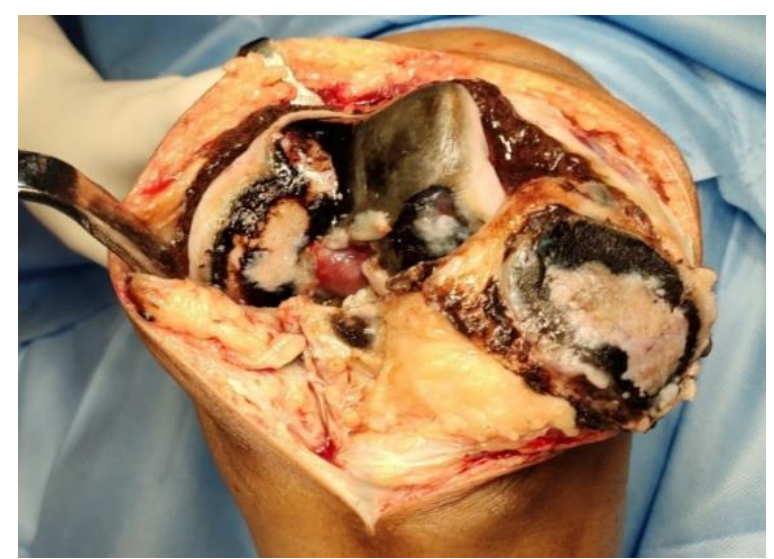

Figure 2. Intra-operative, blackish blue discoloration of knee joint

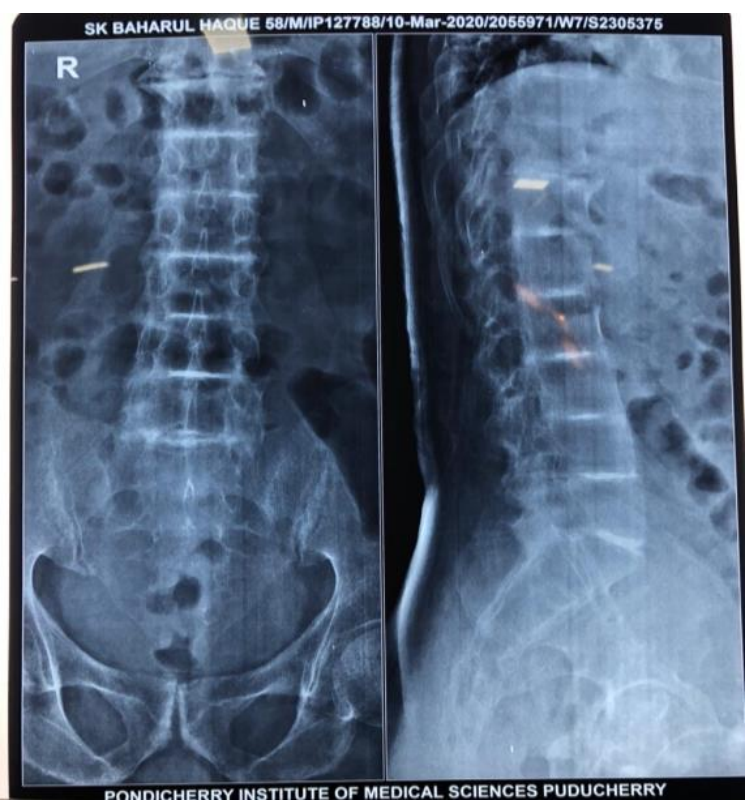

Figure 3. Baffle's spine

After 4 days, patient was again posted for right knee total replacement which was successfully managed with planned Taylor's approach and continuous femoral nerve block. Patient was discharged after 10 days without any complications.

\section{Discussion}

Ochronosis refers to systemic deposition of ochre coloured pigment in cartilages and collagenous tissues. There are two different types of 


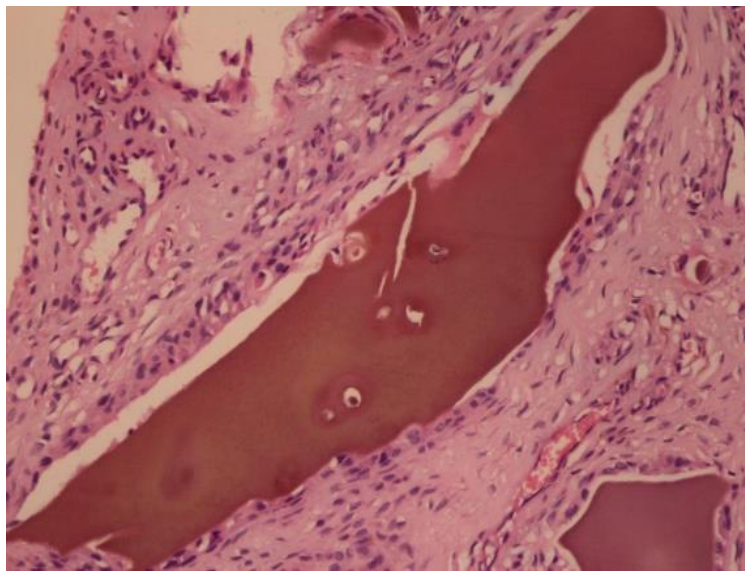

Figure 4. HPE showing brownish black discolouration

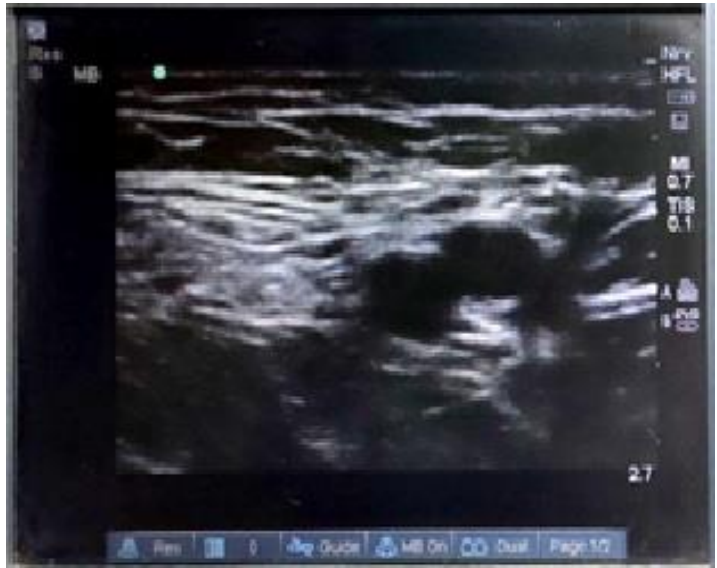

Figure 5. Sonographic image showing femoral nerve anatomy

\begin{tabular}{|c|c|c|}
\hline Systems & Manifestation & Anaesthetic implication \\
\hline Skeletal system & $\begin{array}{l}\text { Pain, cartilage destruction in } \\
\text { shoulder, hip and knee joint results in } \\
\text { joint space loss. } \\
\text { Mild osteophytes and tendon } \\
\text { abnormalities }\end{array}$ & Careful positioning \\
\hline Spine & $\begin{array}{l}\text { Degenerative changes in lumbar and } \\
\text { cervical spine, disc space narrowing } \\
\text { and calcification, vertebral } \\
\text { osteoporosis and osteophytosis, } \\
\text { Baffle's spine. } \\
\text { Restricted range of motion of cervical } \\
\text { spine, neurological symptoms }\end{array}$ & $\begin{array}{l}\text { Preoperative neurological } \\
\text { examination } \\
\text { Difficult regional blocks } \\
\text { Difficult laryngoscopy and } \\
\text { intubation }\end{array}$ \\
\hline Airway & $\begin{array}{l}\text { Pigment deposition in the larynx, } \\
\text { trachea and narrowing of glottic } \\
\text { opening }\end{array}$ & $\begin{array}{l}\text { Small endotracheal tube } \\
\text { Difficult airway cart should be } \\
\text { readily available }\end{array}$ \\
\hline Respiratory system & Restrictive pulmonary disease & $\begin{array}{l}\text { Preoperative } \\
\text { function testing }\end{array}$ \\
\hline $\begin{array}{l}\text { Cardiovascular } \\
\text { system }\end{array}$ & $\begin{array}{l}\text { Valvular heart disease, accelerated } \\
\text { atherosclerosis, coronary artery } \\
\text { disease, conduction abnormalities }\end{array}$ & $\begin{array}{l}\text { Preoperative } 12 \text { lead ECG, } \\
\text { Echocardiography, Intensive } \\
\text { intraoperative monitoring }\end{array}$ \\
\hline
\end{tabular}

Ochronosis; exogenous and endogenous. Ochronosis affects the skeletal, respiratory, cardiovascular, genitourinary, cutaneous and ocular systems. ${ }^{4}$ These clinical manifestations become evident only around fourth decade of life due to the pigment deposition within the affected tissues. ${ }^{5}$

Because of spine involvement both general anesthesia and central neuraxial anesthesia possess challenges to the anaesthetist. Hence a variation of the paramedian approach, the lumbosacral approach described by Taylor can be used as a rescue anaesthetic technique. This technique is carried out at L5-S1 interlaminar space $1 \mathrm{~cm}$ medial and $1 \mathrm{~cm}$ caudal to the lower most prominence of the posterior inferior iliac spine in a cephalo-medial direction. This is an alternative technique when standard approach at 
L3-4 and L4-5 spaces fails. This is a very useful method in case of spinal fusion, arthritic joints, spinal deformity, skin infection in the lumbar region or in other conditions in which the usual approach is difficult or impossible. ${ }^{6,8}$

It is the lowest and widest lumbar space with least chances of trauma to the spinal cord. This space is least affected by arthritic and degenerative changes and, hence Taylor's approach is a better alternative to midline approach. ${ }^{9}$ It is described in various textbooks as an alternative to standard midline approach, but the success depends on the acquisition of knowledge and skills to perform it. Frequent hands-on training and teaching this technique increase the safety and success rate in difficult cases. Chalapathy et al ${ }^{9}$ conducted a study to know the success rate of Taylor's approach in patients with deformed spines among residents and found $94 \%$ success rate with a $6 \%$ acceptable failure rate. There are many case reports in the literature on Taylor's approach for various spinal deformities but for alkaptonuria the literature is very little as the condition itself is quite rare.

In a study by Shanthanna et $\mathrm{al}^{10}$ showed superiority of femoral nerve block over epidural in patients undergoing total knee replacement. Peripheral nerve block has the advantage of sparing motor control in one leg to allow for early mobilization with crutches, avoid post-operative delirium and epidural associated systemic side effects.

\section{Conclusion}

Anaesthetists should have a good knowledge about various anaesthetic techniques and a flexible anaesthetic plan that best suites the patient to proceed when encountered with unexpected problems as in this case. Taylor's approach for spinal anaesthesia is indeed a rescue technique in cases of difficult spine and avoids the airway manipulation in patients with anticipated difficult intubation by avoiding general anaesthesia.

\section{References}

1. Van Offel JF, De Clerck LS, Francx LM et al. The clinical manifestations of Ochronosis: a review. Acta Clin Belg 1995; 50: 358-62.

2. Ravindra Pandey, Anil Kumar, Rakesh Garget al. Perioperative management of patient with alkaptonuria and associated multiple comorbidities. $J$ Anaesth clinpharmacol 2011; 27: 259-61.

3. Fisher AA, Davis MW. Alkaptonuric Ochronosis with Aortic valve and joint Replacements and femoral fracture: A case report and literature review. Clinical Medicine and Research 2004; 2: 209-15

4. Casselman F, Herijgers P, Meyns B, et al. Aortic stenosis in endogenous ochronosis. $J$ Heart Valve Dis 1999; 8: 445-6

5. Sahin G, Milcan A, Bagis S, et al. A case of ochronosis: upper extremity involvement. Rheumatol Int. 2001; 21(2):78-80.

6. R. Collins, Principles of Anaesthesiology General and Regional Anaesthesia 3 (Philadelphia: Lea and Febiger 1993) pg1466.

7. G. Edward Morgan, Jr, MD, Maged S, Mikhail, MD ,Michael J, Murray, MD, PhD. Clinical Anaesthesiology 4 (United states of America: the McGraw Hill Companies 2006) 290-308.

8. Gupta K, Rastogi B, Gupta PK et al. Subarachnoid block with Taylor's approach for surgery of lower half of the body and lower limbs: A clinical teaching study. Anesth Essays Res 2012; 6: 38-41.

9. Chalapathy P, Jayasundaram E. Taylor's approach is the best approach to overcome difficulty in lumbar puncture in difficult spinal cases. IOSR-JDMS 2016; 15(12): 1115.

10. Shanthanna H, Huilgol M, Manivackam VK et al. Comparative study of ultrasound guided continuous femoral nerve blockade with continuous epidural analgesia for pain relief following total knee replacement. Indian $J$ Anaesth 2012; 56: 270-5. 